\title{
Role of interleukin 1 and interleukin 1 receptor antagonist in the mediation of rheumatoid arthritis
}

\author{
Michael H Schiff
}

\begin{abstract}
Chronic arthritis is characterised by chronic joint inflammation and concurrent joint erosion and destruction. The inflammatory cytokine interleukin 1 (IL1) has been shown to be a key mediator in the autoimmune disease rheumatoid arthritis (RA). Interleukin 1 mediates bone resorption and cartilage destruction, but may not play as dominant a part in joint swelling and inflammation. Interleukin 1 receptor antagonist (IL1Ra) selectively inhibits the effects of IL1 by competing for the IL1 receptor on all surfaces of the synovium. In a randomised controlled trial in 472 patients with active disease, IL1Ra 30 mg/day, $75 \mathrm{mg} /$ day or $150 \mathrm{mg} /$ day given by subcutaneous injection significantly reduced the signs and symptoms of RA at 24 weeks. An American College of Rheumatology (ACR) $20 \%$ response was seen in $43 \%$ of the patients treated with 150 $\mathrm{mg} / \mathrm{day}$ at 24 weeks. IL1Ra was well tolerated; injection site reactions were the most common adverse event. In another trial, in 419 patients with active RA treated concomitantly with methotrexate, there were ACR 20\% responses after 24 weeks in $42 \%$ of the patients treated with 1 $\mathrm{mg} / \mathrm{kg} / \mathrm{day}$ by subcutaneous injection and in $35 \%$ of those treated with $2 \mathrm{mg} / \mathrm{kg} / \mathrm{day}$. I1Ra offers a unique selective, targeted mechanism of action to block the IL1 mediated effects of RA.

(Ann Rheum Dis 2000;59(suppl I):i103-i108)
\end{abstract}

Rheumatoid arthritis (RA) has puzzled medical science for centuries. It is a chronic systemic inflammatory disease that occurs almost three times as often in women as in men, mainly affecting those between the ages of 29 and 50 years. The crippling disorder may have a sudden onset, and often has a poor prognosis. When the signs of the disease are not clear, RA can remain undiagnosed for years and can continue to progress. Recent research has better defined the biology of RA and has identified several cytokine messengers as responsible for

Dr Schiff

(dacdac2@worldnet.att.net) the destruction in the affected joints throughout the body. ${ }^{1}$

In RA, an unknown environmental agent such as a virus or toxin triggers an autoimmune response in genetically susceptible persons. This innate response first evolved in microorganisms as a defence against microbial invasion, and differs from the acquired (memory type) immune response. ${ }^{2}$ The innate (natural or non-specific) immune response works to neutralise and destroy invading microorganisms, reduce tissue injury and cell death, promote recovery and decrease the risk of opportunistic infections. ${ }^{3}$ It produces internal mediators, particularly the cytokines, to ward off the invading agent. Cytokines increase the production of migrating defence cells, including macrophages, neutrophils and chondrocytes. The overproduction of specific cytokines, such as interleukin 1 (IL1) and tumour necrosis factor $\alpha(\mathrm{TNF} \alpha)$, drives pathophysiological processes that lead to the clinical symptoms of RA. ${ }^{1245}$ Studies have shown that IL 1 and TNF $\alpha$ have overlapping proinflammatory effects in patients with RA (table 1 ). ${ }^{6}$

New treatment strategies for RA target these mediators of the inflammatory response. An avenue of therapeutic entry is the cytokine network that regulates the innate immune system. Studies in animals and humans have identified IL1 as a pivotal mediator in the disease process. Patients with active RA have been shown to have increased plasma concentrations of IL $1 \beta .^{7}$ Three cytokines, IL1, IL6 and TNF $\alpha$, seem to play important parts in initiating and regulating the innate immune response. ${ }^{6}$ Evidence indicates that IL1 acts as a comitogen for T lymphocytes, while $\mathrm{TNF} \alpha$ transmits the $\mathrm{T}$ helper cell type $1 \mathrm{~T}$ cell response and IL6 promotes B lymphocyte growth. ${ }^{2}$

\section{Role of IL1}

IL1 serves as the prototypic "alarm" cytokine in healthy persons, affecting nearly every tissue and organ in the body. The induction of IL1 by a virus, bacterium or toxin leads to the production of several other proteins, including $\mathrm{TNF} \alpha$, IL6 and IL1 receptor antagonist (IL1Ra), through cytokine production or signalling pathways. ${ }^{128}$ Some of the cytokine pathways induce immunological mechanisms, and others produce haematological changes. IL1 is produced by a variety of cells that are part of the innate immune system. There is increasing evidence that constant activation of the innate immune system occurs in several chronic inflammatory processes, including RA. ${ }^{2}$ This 


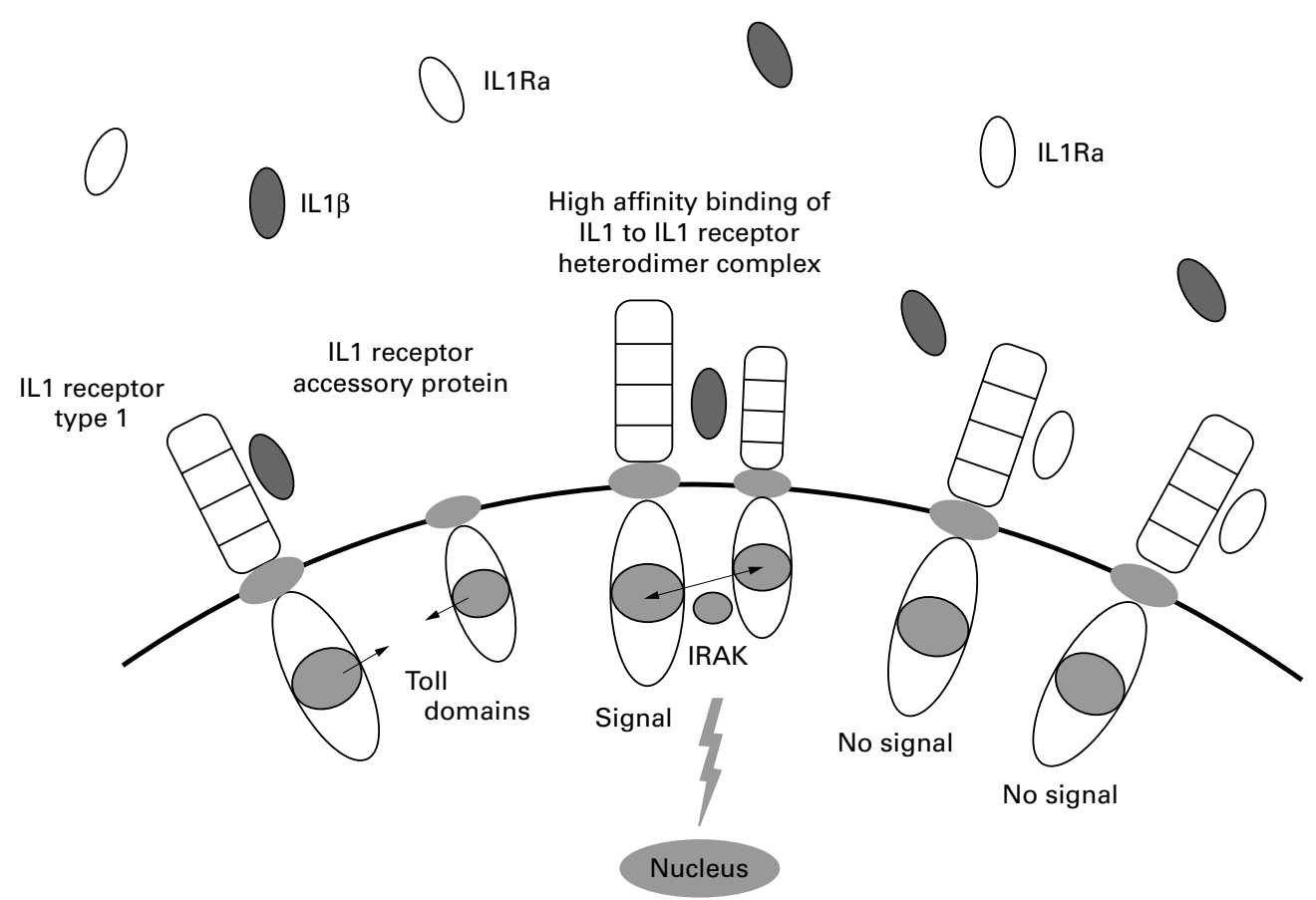

Figure 1 IL1Ra binds to IL1 receptor type I but does not activate the cell. ${ }^{2}$

persistent activation promotes constitutional changes, metabolic abnormalities and destruction and remodelling of tissues in persons with chronic, uncontrolled disease. ${ }^{9}$ Experiments have found that the administration of IL1 stresses host defences and mediates the response to disease. In animal and human studies, overproduction or continued production of IL1 compromises host defences in autoimmune disorders such as RA. ${ }^{10}$ Thus, reducing the synthesis of IL1 or blocking the effects of an overabundance of IL1 may offer a therapeutic option for such conditions.

IL 1 causes inflammatory cells to move into the structures of joints and the synovium in patients who have RA. A currently unknown antigenic trigger activates the production of IL1 in the joint by macrophages (lymphocytes, monocytes and transformed fibroblasts). ${ }^{11}$ These cells further produce or secrete additional cellular messengers such as the proteoglycans and proteases that can lead to the formation of the pannus, which accumulates in the joints. Destructive enzymes can then go on to destroy cartilage and ultimately degrade and erode bone. Selectively and specifically blocking IL1 is a targeted, rational treatment against the destructive effects of this cytokine in RA. ${ }^{13}$

At the cellular level, IL1 induces other cytokines, including IL6 and TNF $\alpha .{ }^{12} \mathrm{TNF} \alpha$ is a very potent inducer of IL1 in animal studies. Together, IL1 and TNF $\alpha$ act synergistically to cause further damage to the joints in patients with RA. ${ }^{14}$ This relation between cytokine pathways may explain why, although $\mathrm{TNF} \alpha$ may not be a direct cause of RA, anti-TNF based treatment may have a therapeutic effect in some patients (J I Frishman et al, European League Against Rheumatism (EULAR) Nice, France, 2000 and Van den Berg $\left.{ }^{15}\right)$.

In animal models of RA, both IL1 and $\mathrm{TNF} \alpha$ seem to play a crucial part in causing the degradation of proteoglycans that can damage the joints. ${ }^{216}{ }^{17}$ Local production of IL1 in the early immune complex arthritis model in the mouse shows this cytokine to be directly responsible for the inhibition of proteoglycan synthesis. ${ }^{16}$ IL1 and TNF $\alpha$ may act synergistically to mediate parts of the inflammatory process. However, some data suggest that IL $1 \alpha$ in fibroblasts may serve as the endogenous mediator of joint damage in RA. ${ }^{18}$

IL1 also seems to promote joint breakdown by attracting inflammatory leucocytes and activating synovial cells. $\mathrm{TNF} \alpha$ seems to have no effect on any of these promoters of RA: the deleterious cell influx, proteoglycan synthesis or proteoglycan degradation. ${ }^{19}$ Some animal research suggests a "decoupling" of the IL1 and TNF $\alpha$ pathways, with IL1 performing the pivotal role in this disease. ${ }^{1520}$ There seems to be a dysregulation of IL1Ra production and a failure to modulate the effects of IL1 $\beta$ in people with RA. ${ }^{21}$

\section{The action of IL1Ra and its recombinant form}

IL1ra, the first described naturally occurring specific receptor antagonist of any cytokine or hormone, was discovered in the $1980 \mathrm{~s}^{22}$ The

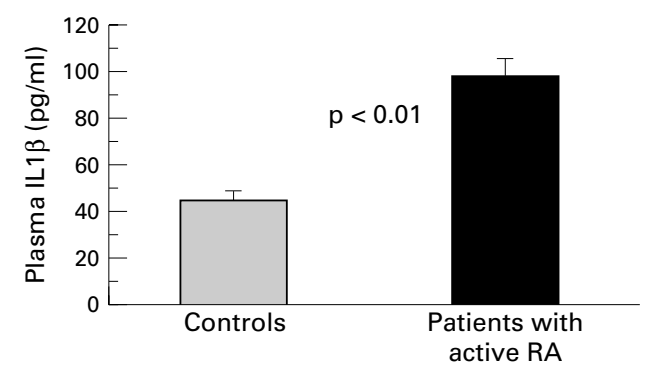

Figure 2 Plasma concentrations of IL1 $\beta$ in controls and patients with active $R A$. $^{\text {? }}$ 


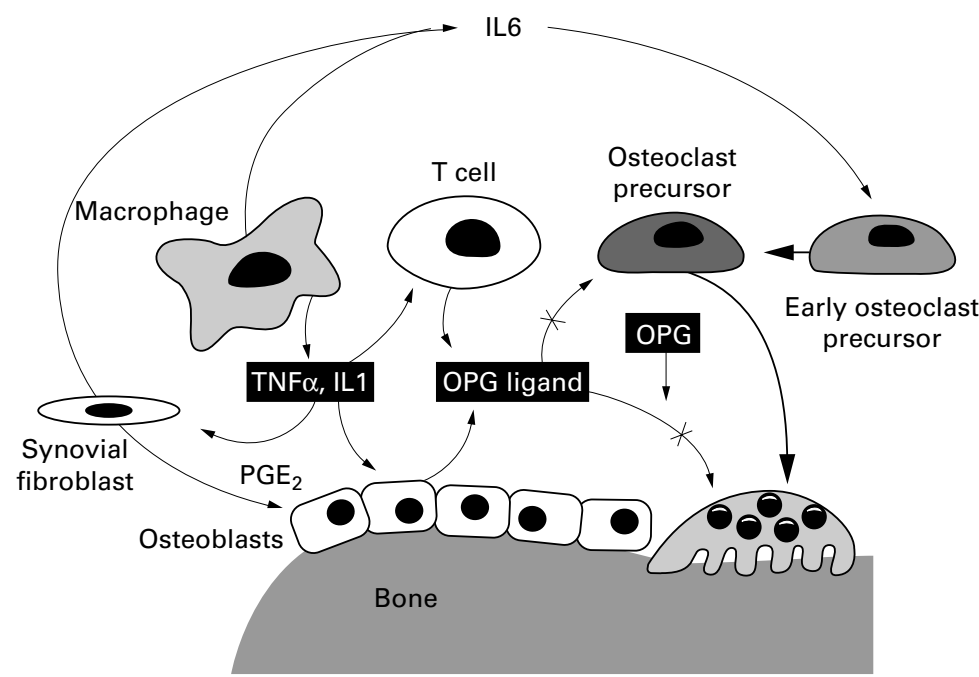

Figure 3 Cytokine regulation of osteoclast differentiation and activation. OPG, osteoprotogerin; $P G E_{2}$, prostaglandin $E_{2}$. (Courtesy of $M H$ Schiff).

Table 2 Design of European Monotherapy Study

\begin{tabular}{ll}
\hline Design & Six month randomised double blind placebo controlled dose ranging study \\
& DMARDs discontinued six weeks before enrollment \\
Dose & Placebo or IL1Ra 30,75 or $150 \mathrm{mg} / \mathrm{kg} /$ day sc \\
Patients & 472 patients with active RA \\
Location & 41 sites in 11 European countries \\
\hline
\end{tabular}

DMARDs, disease modifying antirheumatic drugs. Adapted from Bresnihan et al. ${ }^{33}$

Table 3 Patient details in European Monotherapy Study

\begin{tabular}{lllll}
\hline & \multicolumn{5}{c}{ IL1Ra } \\
\cline { 3 - 5 } & $\begin{array}{c}\text { Placebo } \\
(n=121)\end{array}$ & $\begin{array}{l}30 \mathrm{mg} \\
(n=119)\end{array}$ & $\begin{array}{l}75 \mathrm{mg} \\
(n=116)\end{array}$ & $\begin{array}{l}150 \mathrm{mg} \\
(n=116)\end{array}$ \\
\hline Mean age (y) & 52 & 53 & 53 & 54 \\
Mean duration of RA (y) & 3.7 & 4.3 & 4.2 & 3.9 \\
Rheumatoid factor (\% positive) & 69 & 71 & 69 & 69 \\
Erosions (\% positive) & 74 & 77 & 74 & 69 \\
Previous DMARD use (\%) & 81 & 79 & 75 & 66 \\
Corticosteroid use (\%) & 41 & 49 & 41 & 41 \\
NSAID use (\%) & 89 & 82 & 88 & 85
\end{tabular}

$\overline{\text { DMARD, disease modifying antirheumatic drug; NSAID, non-steroidal anti-inflammatory drug. }}$

binding of IL1Ra to the IL1 receptor on the cell surface is almost irreversible, and shows no agonist activity in the body. ${ }^{2}$ Animal research with recombinant human IL1 Ra has shown

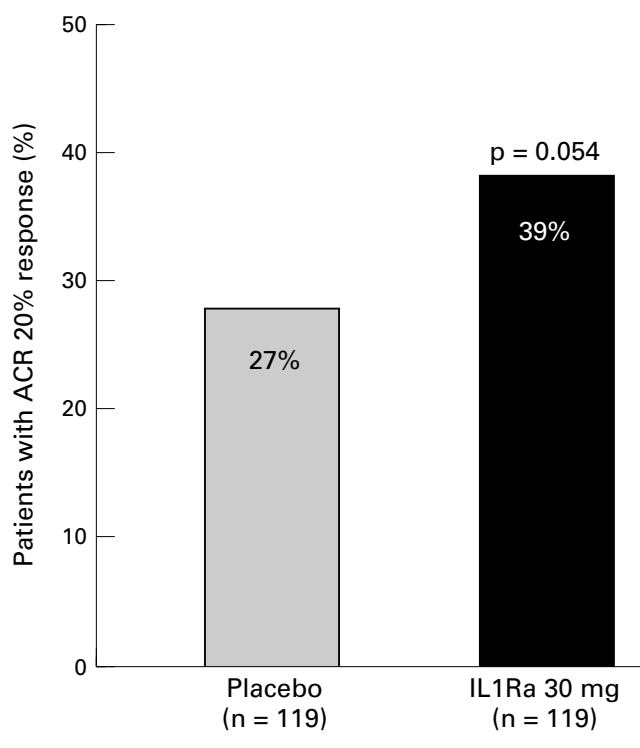

that it selectively and directly blocks IL1 (fig 1). In the rabbit lipopolysaccharide induced arthritis model, the levels of endogenous IL1Ra were too low to suppress the IL1 that mediates the disease. ${ }^{23}$ Endogenous expression of IL1Ra was also a determinant in transgenic mice being susceptible to collagen induced arthritis. ${ }^{24}$

Animal and human studies alike have shown that IL1 and IL1Ra are present in the inflamed synovium and rheumatoid joints, indicating that the IL1 pathway is expressed and regulated within diseased joints. ${ }^{25}{ }^{26}$ Injecting IL1 into the knees of rabbits produced a synovitis with a loss of proteoglycan from the matrix of articular cartilage. ${ }^{27}$ Intravenous injection of IL1Ra into these animals inhibited the entry of leucocytes into the synovial lining and joint cavity and blocked the IL1 caused loss of proteoglycan from the articular cartilage.

Patients with active RA have increased plasma concentrations of IL1 $\beta$ (fig 2). ${ }^{7}$ It has also been found that patients with the highest levels of IL1Ra and lowest levels of IL1 $\beta$ in the synovial fluid had the least troublesome course of Lyme arthritis. ${ }^{28}$ In addition, studies have shown that animals that overexpress IL1Ra are protected against endotoxin caused death. ${ }^{1}$

Clinical findings also suggest that inhibiting IL1 can retard osteoclast activity (fig 3) and downregulate the production of metalloproteinases. This may have the direct effect of preventing the bone erosion that is seen in RA. ${ }^{29}$ The results of a trial to examine this possibility are expected shortly.

Intravenous injection of IL1Ra in healthy volunteers presents overwhelming evidence of the cytokine's role as a pure receptor antagonist in the body. ${ }^{2}$ IL1 Ra showed no agonist activity in humans when given at doses a millionfold greater than the concentration of IL $1 \alpha$ or IL1 $\beta .^{30}$ By occupying the IL1 receptor, IL1Ra effectively stops the IL1 signal transduction that effects the deleterious changes in the synovium and joints in patients with RA (see fig 1).

Figure 4 Clinical response at week 24 in European Monotherapy Study. ${ }^{33}$ 

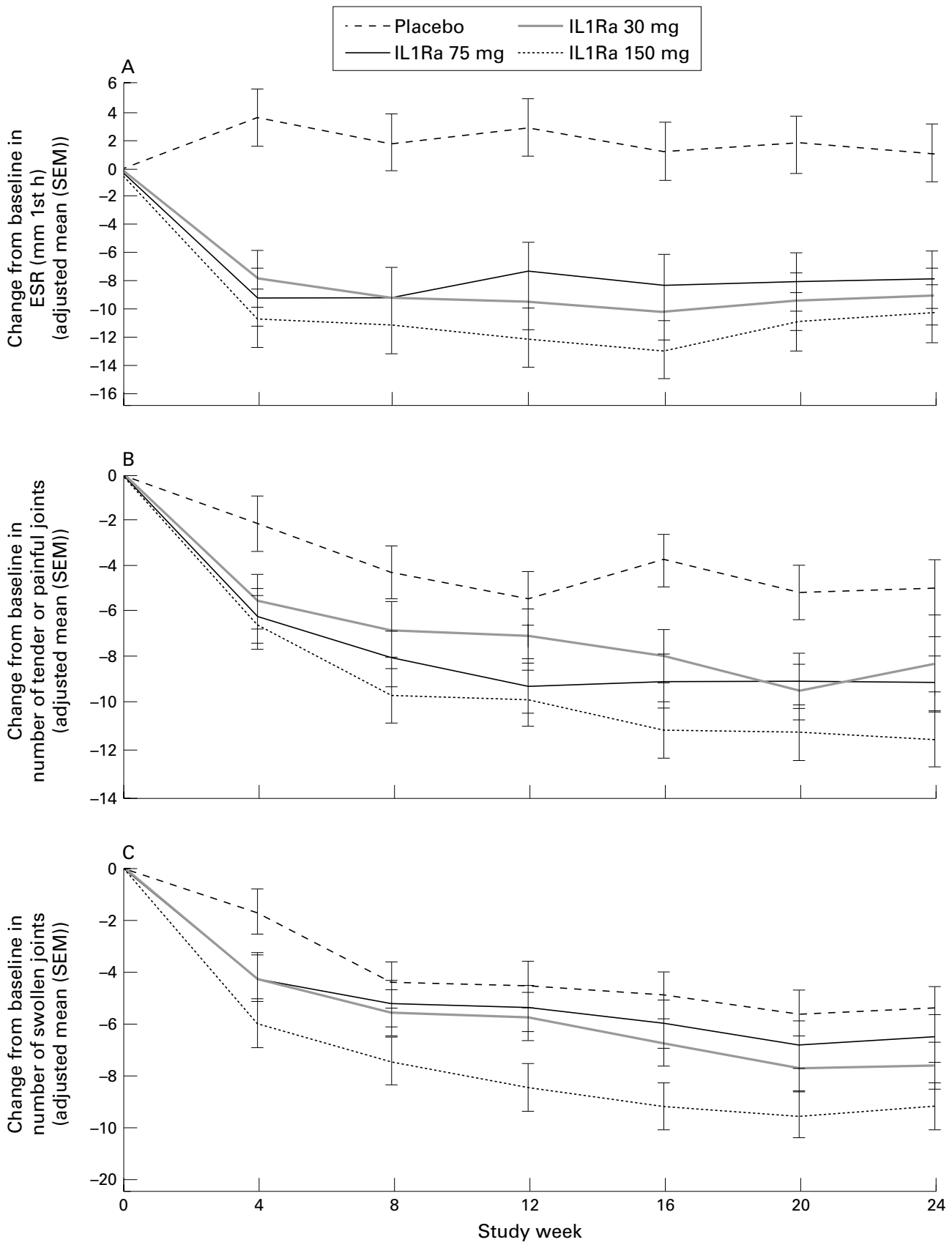

Figure 5 Erythrocyte sedimentation rates (ESRs) (A), inhibition of structural damage by IL1Ra (B) and swollen joint counts (C) in European Monotherapy Study. ${ }^{32}$

\section{Clinical experience}

Studies over the past 10 years in patients with sepsis and RA have shown the excellent safety profile of IL1Ra. It has been used without serious adverse effects in more than 4500 people, including more than 2000 patients with $\mathrm{RA},{ }^{29}$ some for as long as five years.

A randomised double blind placebo controlled trial in 472 patients with RA (tables 2 and 3 ) found that IL1Ra given daily by subcutaneous injection produced a sustained clinical response at week 24, with an American College of Rheumatology (ACR) $20 \%$ response seen in $43 \%$ of the patients treated with the highest dose, $150 \mathrm{mg}$ (fig 4). The administration of IL1Ra significantly reduced other clinical measures of the disease in these patients as well $(p<0.0001$ for erythrocyte sedimentation rates and $p=0.0009$ for the number of tender joints) (fig 5, A and $\mathrm{B}$, respectively). ${ }^{32}$ The $150 \mathrm{mg}$ dose of IL1Ra also significantly decreased the number of swollen joints in patients with moderate to severe RA $(p=0.03)$ compared with placebo (fig 5, C). ${ }^{32}$ An extension of this trial also showed a continued beneficial effect on the disease (fig 6). In this study, patients with RA who were treated with IL1 Ra showed a slowing of radiographic progression in as little as 24 weeks and had a continued benefit with extended treatment for 48 weeks (fig 7).

IL1Ra has also been studied when given concomitantly with methotrexate. ${ }^{34}$ In a randomised double blind placebo controlled trial $(n=419)$ of IL1Ra doses of between 0.04 
Double blind, placebo controlled (weeks 0-24)
Crossover

non-placebo controlled (weeks 25-48)

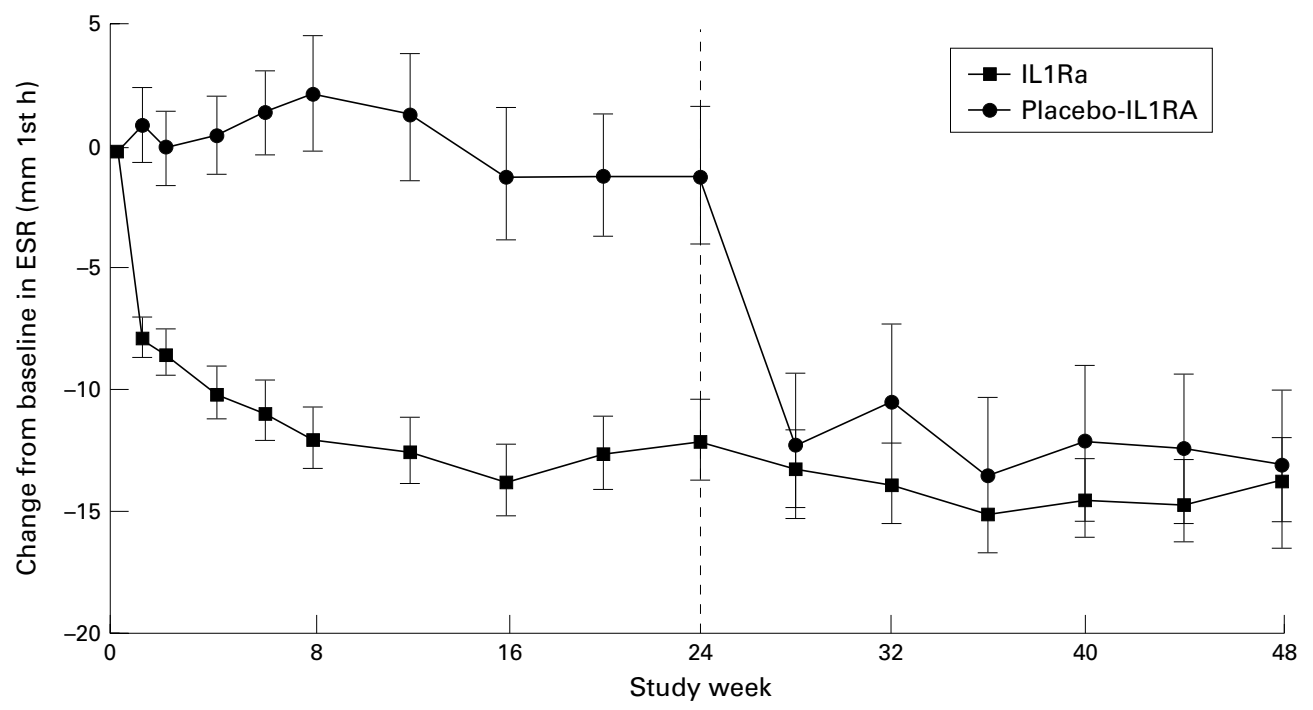

Figure 6 Erythrocyte sedimentation rates (ESRs) in Extension Study of European Monotherapy Study. ${ }^{33}$

$\mathrm{mg} / \mathrm{kg} / \mathrm{day}$ and $2 \mathrm{mg} / \mathrm{kg} / \mathrm{day}$, the $1 \mathrm{mg} / \mathrm{kg}$ and 2 $\mathrm{mg} / \mathrm{kg}$ doses resulted in significant reductions in the signs and symptoms of RA. An ACR $20 \%$ response at week 12 was seen in $46 \%$ of those treated with $1 \mathrm{mg} / \mathrm{kg}$ and in $38 \%$ of those treated with $2 \mathrm{mg} / \mathrm{kg}$, which was generally sustained at week 24 (S B Cohen, 63rd Annual Scientific Meeting of the American College of Rheumatology, Boston, 1999). An ACR 20\% response was seen in $42 \%$ of the patients who completed 24 weeks of treatment with IL1Ra 1 $\mathrm{mg} / \mathrm{kg} /$ day and in $35 \%$ of those who received 2 $\mathrm{mg} / \mathrm{kg} /$ day, but in only $19 \%$ of those given placebo (S B Cohen, 63rd Annual Scientific Meeting of the American College of Rheumatology). IL1Ra was well tolerated, with injection site reactions being the most frequently reported adverse event. The injection site reac-

At week $24 \square$ At week 48

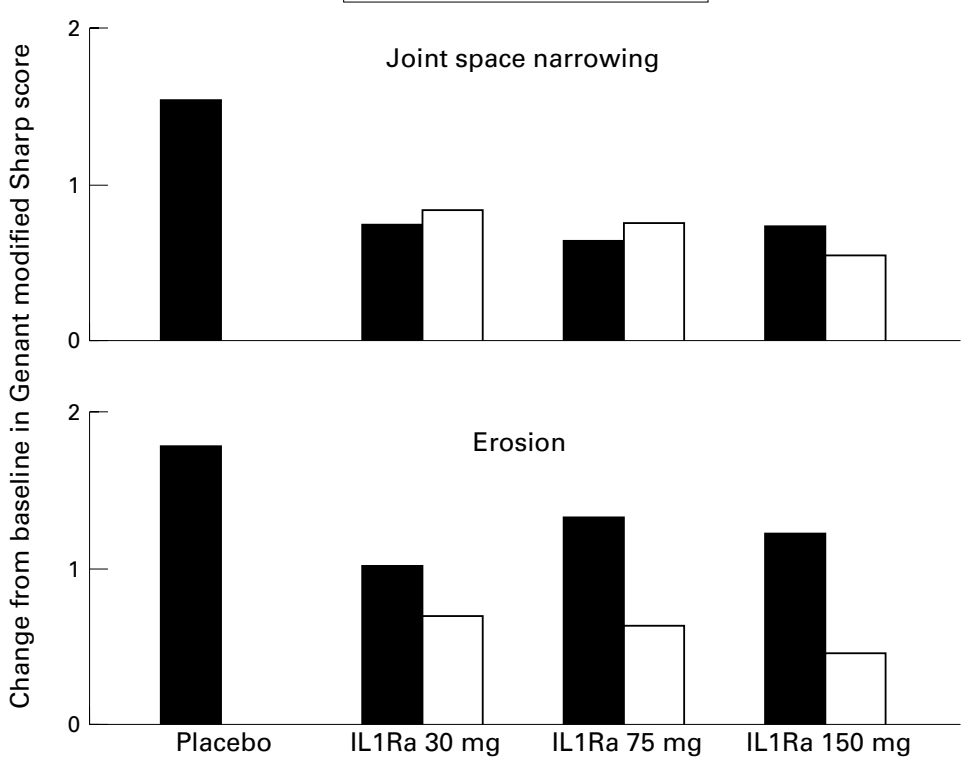

Figure 7 Assessment of joint damage in Extension Study of European Monotherapy Study. ${ }^{33}$ tions generally occurred within the first 28 days of IL1Ra treatment, with $97 \%$ of these transient reactions being mild to moderate. In $87 \%$ of those in whom the adverse events occurred there were only one or two such reactions.

\section{Safety of IL1Ra}

In the clinical trials to date, IL1Ra has been well tolerated. Injection site reactions have been the most frequently observed adverse event, particularly in those given $1 \mathrm{mg} / \mathrm{kg}$ and 2 $\mathrm{mg} / \mathrm{kg}$ doses. The European Monotherapy Study found injection site reactions to be the most frequent (table 4), and there were no changes in creatinine clearance rates or liver enzyme levels. ${ }^{32}$

The adverse effect profile of the cytokine modifiers, such as IL1Ra and TNF $\alpha$ antagonists, is superior to that of the other drug classes that are used to treat RA. Furthermore, the safety record of IL1Ra in terms of risk of infection compares favourably with that of the current biological treatments that target TNF $\alpha$. IL1Ra has shown no evidence of immunosuppression or increased risk of infection or malignancy in controlled clinical trials. $^{29}$

\section{Conclusion}

Stopping the disease process remains the goal of treatment for RA. Recent research has shown this process to include IL1 as pivotal

Table 4 Most common adverse events in European Monotherapy Study

\begin{tabular}{lll}
\hline & \multicolumn{2}{l}{ Patients (\%) } \\
\cline { 2 - 3 } & $\begin{array}{l}\text { Placebo } \\
(n=121)\end{array}$ & $\begin{array}{l}\text { IL1Ra } \\
(n=351)\end{array}$ \\
\hline Injection site reaction & 25 & 68 \\
Exacerbation of RA & 33 & 21 \\
Arthralgia & 12 & 8 \\
Abdominal pain & 5 & 7 \\
Upper respiratory tract infection & 7 & 7 \\
\hline
\end{tabular}


cytokine in initiating disease and the body's natural anti-IL1 response, IL1Ra, to block its effects. Laboratory and animal studies have shown that inhibiting IL1 with either antibodies to IL1 or IL1Ra produces beneficial outcomes. Now, two large well controlled studies in patients with RA have shown that IL1Ra is clinically effective and that it slows progression of bone damage as measured radiographically. Because it is a specific, selective inhibitor of the IL1 pathway, IL1Ra offers an important new treatment for RA that significantly reduces the signs and symptoms of the disease, reduces joint destruction and is safe and well tolerated.

This article was developed, in part, from a presentation by $\mathrm{Dr}$ Schiff at the Second International Symposium on Advances in Schiff at the Second International Symposium on Advances in
Targeted Therapeutics, Miami Beach, Florida, 29 March to 2 Targeted Therapeutics, Miami Beach, Florida, 29 March to 2
April 2000. Dr Schiff has professional relationships with April 2000. Dr Schiff has professional relationships with
Adventis, Amgen, Bayer, Bristol-Myers Squibb, Centocor, Adventis, Amgen, Bayer, Bristol-Myers Squibb, Centocor,
Cypros, Fujisawa, Genelabs, Hoffmann-La Roche, Immunex, Cypros, Fujisawa, Genelabs, Hoffmann-La Roche, Immunex,
Lilly, Merck, Novartis, Parke-Davis, Pfizer, Procter \& Gamble, Silly, Merck, Novartis, Parke-Davis, Pfizer, Procter \& Gamble, made possible, in part, by an unrestricted grant from Amgen Inc.

1 Arend WP, Malyak M, Guthridge CJ, Gabay C. Interleukin-1 receptor antagonist: role in biology. Annu Rev Immunol 1998;16:27-55

2 Dinarello CA, Moldawer LL. Proinflammatory and antiinflammatory cytokines in rheumatoid arthritis: a prime for clinicians. Thousand Oaks (CA): Amgen Inc, 1999.

3 Fearon DT, Locksley RM. The instructive role of innate immunity in the acquired immune response. Science 1996; 272:50-4.

4 Charles P, Elliott MJ, Davis D, Potter A, Kalden JR, Antoni C, et al. Regulation of cytokines, cytokine inhibitors, and acute-phase proteins following anti-TNF-alpha therapy in rheumatoid arthritis. J Immunol 1999;163:1521-8.

5 Matsukawa A, Yoshimura T, Miyamoto K, Ohkawara S, Yoshinaga M. Analysis of the inflammatory cytokine network among TNF alpha, IL-1 beta, IL-1 receptor network among TNF alpha, IL-1 beta, IL-1 receptor
antagonist, and IL-8 in LPS-induced rabbit arthritis. Lab antagonist, and IL-8 in

6 Arend WP, Dayer J-M. Inhibition of the production and effects of interleukin-1 and tumor necrosis factor $\alpha$ in rheumatoid arthritis. Arthritis Rheum 1995;38:151-60.

7 Eastgate JA, Symons JA, Wood NC, Grinlinton RM, di Giovine FS, Duff GW. Correlation of plasma interleukin $1 \mathrm{lev}-$ els with disease activity in rheumatoid arthritis. Lancet 1988;ii:706-9.

8 Philip R, Epstein LB. Tumour necrosis factor as immunomodulator and mediator of monocyte cytotoxicity induced by itself, $\gamma$-interferon and interleukin-1. Nature 1986;323:86-9

9 Moldawer LL, Copeland EM. Proinflammatory cytokines, nutritional support, and the cachexia syndrome: interac-

10 Dinarello C. Interleukin-1 and interleukin-1 antagonism. Blood 1991;77:1627-52.

11 Kelley WN, Ruddy S, Harris ED Jr, Sledge CB, eds. Textbook of rheumatology. Philadelphia: WB Saunders, 1997.

12 Fontana A, Hengartner H, Weber E, Fehr K, Grob PJ, Cohen G. Interleukin 1 activity in the synovial fluid of patients with rheumatoid arthritis. Rheumatol Int 1982;2: $49-53$.

13 Weckmann AN, Alcocer-Varela J. Cytokine inhibitors in autoimmune disease. Semin Arthritis Rheum 1996;26: 539-57.

14 Buchan G, Barrett K, Turner M, Chantry D, Maini RN, Feldmann $M$. Interleukin-1 and tumor necrosis factor mRNA expression in rheumatoid arthritis: prolonged production of IL-1 $\alpha$. Clin Exp Immunol 1988;73:449-55.
15 Van den Berg WB. Lessons for joint destruction from animal models. Curr Opin Rheumatol 1997;7:161-7.

16 Saklatvala J. Tumour necrosis factor $\alpha$ stimulates resorption and inhibits synthesis of proteoglycan in cartilage. Nature 1986;322:547-9.

17 Neidel J, Schulze M, Lindschau J. Association between degree of bone-erosion and synovial fluid-levels of tumor necrosis factor $\alpha$ in the knee-joints of patients with rheumatoid arthritis. Inflamm Res 1995;44:217-21.

18 Apte RN. Intracellular IL-1 alpha in fibroblasts as a possible endogenous mediator of joint damage in rheumatoid arthritis. Isr J Med Sci 1997;33:285-8.

19 van Lent PLEM, van de Loo FAJ, Holthuysen AEM, van den Bersselaar LAM, Vermeer H, van den Berg WB. Major role for interleukin 1 but not for tumor necrosis factor in early cartilage damage in immune complex arthritis in mice. J Rheumatol 1995;22:2250-8.

20 van den Berg WB. Joint inflammation and cartilage destruction may occur uncoupled. Springer Semin Immunopathol $1998 ; 20: 149-64$.

21 Chikanza IC, Roux-Lombard P, Dayer J-M, Panayi GS. Dysregulation of the in vivo production of interleukin-1 receptor antagonist in patients with rheumatoid arthritis. Arthritis Rheum 1995;5:642-8.

22 Arend WP. Interleukin-1 receptor antagonist: discovery, tructure and properties. Prog Growth Factor Res 1990;2: 193-205.

23 Matsukawa A, Ohkawara S, Maeda T, Takagi K, Yoshinaga $\mathrm{M}$. Production of IL-1 and IL-1 receptor antagonist and the pathological significance in lipopolysaccharide-induced arthritis in rabbits. Clin Exp Immunol 1993;93:206-11.

24 Ma Y, Thornton S, Boivin GP, Hirsch D, Hirsch R, Hirsch E. Altered susceptibility to collagen-induced arthritis in transgenic mice with aberrant expression of interleukin-1 receptor antagonist. Arthritis Rheum 1998;41:1798-805.

25 Deleuran BW, Chu CQ, Field M, Brennan FM, Katsikis P, Feldmann $M$, et al. Localization of interleukin-1 alpha, type 1 interleukin-1 receptor and interleukin-1 receptor antagonist in the synovial membrane and cartilage/pannus nist in the synovial membrane and cartilage/pannus junction

26 Hopkins SJ, Humphreys M, Jayson MI. Cytokines in synovial fluid, I: the presence of biologically active and mmunoreactive IL-1. Clin Exp Immunol 1988;72:422-7.

27 Henderson B, Thompson RC, Hardingham T, Lewthwaite J. Inhibition of interleukin-1-induced synovitis and articular cartilage proteoglycan loss in the rabbit knee by recombinant human interleukin-1 receptor antagonist. Cytokine 1991;3:246-9.

28 Miller LC, Lynch EA, Isa S, Logan JW, Dinarello CA, Steere AC. Balance of synovial fluid IL-1 beta and IL-1 receptor antagonist and recovery from Lyme arthritis. Lancet 1993;341:146-8.

29 Data on file, IL1Ra. Thousand Oaks (CA): Amgen Inc.

30 Granowitz EV, Porat R, Mier JW, Pribble JP, Stiles DM, Bloedow DC, et al. Phamacokinetics, safety and immunomodulatory effects of human recombinant interleukin-1 receptor antagonist in healthy humans. Cytokine 1992;4: 353-60.

31 Smith JW, Urba WJ, Steis R, Janik J, Sharfman W, Fenton R, et al. Phase II trial of interleukin-1 alpha in combination with indomethacin in melanoma patients. [Abstract]. Proc Am Soc Clin Oncol 1991;10:293.

32 Bresnihan B, Alvaro-Gracia JM, Cobby M, Doherty M, Domljan Z, Emery P, et al. Treatment of rheumatoid arthritis with recombinant human interleukin-1 receptor antagonist. Arthritis Rheum 1998;41:2196-204.

33 Jiang Y, Genant HK, Watt I, Cobby M, Bresnihan B, Aitchison R, McCabe D. A multicenter, double-blind, dose-ranging, randomized and placebo controlled study of recombinant human interleukin-1 receptor antagonist in patients with rheumatoid arthritis: radiologic progression and correlation of Genant and Larsen scoring methods. and correlation of Genant and L

34 Cohen S, Hurd E, Cush JJ, Schiff MH, Weinblatt ME, Moreland LW, et al. Treatment of interleukin-1 receptor antagonist in combination with methotrexate (MTX) in rheumatoid arthritis (RA) patients. [Abstract]. Arthritis Rheum 1999;42 (suppl 9):S273. 